\title{
ENSINO DO URBANISMO NOS CURSOS DE ARQUITETURA E URBANISMO: TECENDO A COMPREENSÃO DA CIDADE PARA A ATIVIDADE PROJETUAL
}

Urban planning teaching in Architecture and Urbanism courses: weaving the understanding of the city for design activity

Mônica Peixoto Vianna', Débora Barros Cavalcanti²

RESUMO Este artigo trata de uma reflexão sobre o ensino do urbanismo e sua articulação com a atividade projetual em escolas de Arquitetura e Urbanismo a partir da elaboração e implantação de um projeto pedagógico inovador para um curso de Arquitetura e Urbanismo na região Nordeste do Brasil. Como relato de experiência, inicialmente o artigo tratará as bases conceituais e empíricas que deram origem à construção de uma visão crítica sobre os cursos de Arquitetura e Urbanismo na região. Em seguida serão abordados os critérios que foram a base deste novo projeto pedagógico e algumas estratégias adotadas para o ensino de urbanismo, principalmente a inclusão de uma disciplina que trata de planejamento urbano no primeiro semestre do curso e uma atividade de reconhecimento da cidade como palco da ação do arquiteto e urbanista. Por ser uma experiência ainda recente, serão relatadas as primeiras avaliações feitas por docentes e alunos sobre a aplicação prática dos critérios mencionados.

PALAVRAS-CHAVE: Ensino do urbanismo, Projeto pedagógico, Relação entre arquitetura e urbanismo, Inovação.

\begin{abstract}
This article is a reflection on the urban planning teaching and its integration with the design activity in Architecture and Urbanism schools by the development and implementation of an innovative degree programme for a course of Architecture and Urban Planning in the Brazilian Northeast area. As experience report, initially the article will address the conceptual and empirical grounds that gave rise to the construction of a critical view of the Architecture and Urbanism courses in this region. Then, we will discuss the criteria that were the basis of this new programme and some strategies adopted for urban planning teaching, especially the inclusion of a discipline that deals with urban planning in the first semester of the course. Since it is a still recent experience, the first evaluations made by teachers and students on the practical application of the above criteria will be reported.
\end{abstract}

KEYWORDS: Urban education, Degree programme, Interface between architecture and urban planning, Innovation.

\section{How to cite this article:}

VIANNA, M. P.; CAVALCANTI, D. B. Ensino do urbanismo nos cursos de Arquitetura e Urbanismo: tecendo a compreensão da cidade para a atividade projetual. Gestão e Tecnologia de Projetos, São Carlos, v. 11, n. 1, p. 121-133, jan./jun. 2016.

http://dx.doi.org/10.11606/gtp.v11i1.99209
Fonte de financiamento: Declara não haver. Conflito de interesse: Declara não haver. Submetido em: 20 jun. 2015 Aceito em: 14 jan. 2016 


\section{INTRODUÇÃO}

A relação entre a arquitetura e o urbanismo foi construída ao longo do tempo de maneira indissociável. Segundo Brandão (2005), arquitetos foram assumindo, historicamente, diferentes papéis, mas sempre conectados com a sociedade do seu tempo e o espaço decorrente: o arquiteto-sacerdote da antiguidade; o arquiteto-filósofo da Grécia antiga; o arquiteto orgulhoso do Império Romano que ia estendendo sua influência e criando novas cidades; o arquiteto-operário medieval; o arquiteto-mediador do Renascimento que se preocupava com a estética das cidades; o arquiteto do estado na Revolução Industrial tratando de resolver os problemas decorrentes da crescente e acelerada urbanização; o arquiteto liberal do século XX que não resiste à cultura homogeneizante dominante e à submissão ao mercado e acaba se transformando, como todos os seres humanos, em apêndices do capital (ROGGERO, 2010). Sendo assim, o arquiteto e urbanista negligencia parte da sociedade (talvez a maior), tornando-se parcial, optando por trabalhar para um determinado grupo social. Essa escolha representa uma perda na relevância social da profissão, pois ao privatizar o seu público alvo, menospreza a cidade como palco de sua ação por excelência onde há muito trabalho a realizar. A arquitetura e o urbanismo se tornam artigo de luxos e não uma necessidade (FRANÇA et al., 2013).

Seguindo a mesma dinâmica, o ensino de arquitetura e urbanismo reflete historicamente esse contexto universal, não considerando, em muitos casos, as realidades locais. A construção de uma relevância social estava presente no imaginário e na prática dos que fizeram dessa profissão algo que poderia, em seu objetivo final, melhorar a qualidade de vida dos habitantes de determinada localidade, partindo da concepção dos espaços micro (como um banheiro) ao macro (bairros e cidades, por exemplo). Com as crises que se sucederam na área da construção civil e do desenvolvimento urbano no final do século XX, as escolas se distanciaram dessa visão e se adaptaram ao mercado, desenvolvendo, de forma expressiva, a formação do arquiteto projetista autônomo que atende às camadas de maior renda da população, em detrimento de um profissional pronto a contribuir na solução dos problemas espaciais das aglomerações urbanas nas diferentes escalas e características (MARAGNO, 2013). Alia-se o fato de que a área de projetos trabalha de forma pouco centrada na realidade local e a partir de pressupostos universais. Essa carência na formação acabou distanciando os arquitetos e urbanistas da realidade local fazendo que, ao se tornarem irrelevantes e despreparados, para enfrentar tal realidade, o mercado de trabalho não reconhecesse o valor da profissão, trazendo vários problemas que vão da baixa remuneração à substituição por outros profissionais em tarefas nas quais o arquiteto e urbanista estaria, em tese, mais preparado para realizá-las (tais como a habitação de interesse social).

Sendo assim, este artigo tratará de desenhar esse panorama geral e apresentar os pressupostos que estiveram na base da concepção de um Projeto Pedagógico de Curso de Arquitetura e Urbanismo que fosse mais sensível às questões locais, demonstrando que a adoção de determinadas posturas e abordagens podem dar ao curso uma relevância social, em algumas regiões perdida e substituída por outras profissões que não podem atender completamente o alcance da disciplina de Arquitetura e Urbanismo. Apresenta-se a seguir o resultado dessa reflexão em forma de um projeto pedagógico de um curso de Arquitetura e Urbanismo na região Nordeste que, tendo apenas 16 meses, já demonstra resultados passíveis de avaliação. Apesar de saber que a problemática da relevância social do arquiteto e urbanista e a consequente crise da profissão tem um caráter mundial, este artigo trata de analisar a questão tendo como pano de fundo uma cidade de porte médio de um pequeno estado nordestino. Sendo assim, a baixa qualidade do espaço arquitetônico, em termos micro e macro, encontrada em Maceió reflete a irrelevância social que a profissão vem assumindo nos últimos anos. 
Inicialmente o artigo analisará brevemente a formação do arquiteto e urbanista, construindo uma visão crítica sobre os cursos de Arquitetura e Urbanismo na região. Em seguida serão destacados os critérios que foram definidos como a base do novo projeto pedagógico e algumas estratégias adotadas para o ensino de urbanismo, especialmente detalhando uma atividade integradora que buscou introduzir os alunos no conhecimento da cidade e dos seus problemas e potencialidades. Para finalizar, ainda de forma incipiente por causa da contemporaneidade da experiência, buscarse-á avaliar os frutos por meio dos relatos de alunos e docentes sobre a aplicação prática dos critérios mencionados.

\section{A ATUAÇÃO E A FORMAÇÃO DO ARQUITETO E URBANISTA}

Este artigo não aprofunda a questão da profissão do arquiteto e urbanista enquanto suporte de uma produção arquitetônica ideológica que promove especulação imobiliária, ignora as populações de baixa renda e degrada o meio ambiente - uma vez que já fora discutida por Paulo Bicca (1984) em Arquiteto, a máscara e a face, que sugere uma autonegação da profissão -, mas retoma o tema pelo viés da autocrítica, como sugere Lauande (2005) em seu artigo "As velhas e novas máscaras do arquiteto". A arquitetura e o urbanismo, apesar de sua ampla abordagem e possibilidades de atuar como agente transformador das condições socioespaciais locais, têm se dedicado a pequenas porções das suas atribuições, as que estão ligadas à manutenção de uma imagem "glamourosa" da vida, da existência de um status cuja possibilidade de pagar um arquiteto é um sinal de distinção social. Não se trata de criticar os profissionais que atendem a essa fatia do mercado, eles o fazem e com muita competência, no entanto apoia-se aqui a análise de Lauande (2005) que posiciona o arquiteto e urbanista como refém do estereótipo de "maquiador de espaços":

Os eventos "barrocos" como a Casa Cor, passaram a ser para a sociedade a maior "vitrine" da nossa produção. Os espaços concebidos são um mero show-room travestido de "arquitetura", a serviço (promíscuo) da lógica do mercado, com a sua ávida necessidade de renovar a oferta de produtos.

Lauande (2005) complementa a sua crítica ao afirmar que reconstruir a relevância social do arquiteto envolve o desvencilhamento das máscaras para que a contribuição do arquiteto e urbanista atue no resgate de uma sociedade refém não só das injustiças sociais, mas também, da submissão ao poder das imagens e da mídia. Dever-se-ia, portanto, retomar o papel do arquiteto e urbanista enquanto pensador da sua ação e da sociedade que lhe rodeia, tendo em vista que o espaço reflete a forma como a sociedade se organiza. A formação desse profissional consequentemente deve tratar a estética de maneira indissociável da ética e assim praticar uma autocrítica do que tem sido a sua produção e influência na sociedade atual. Desse ponto de vista filosófico, pela abrangência da formação acadêmica do arquiteto e urbanista, esse profissional deveria ser imprescindível para a sociedade.

Observam-se, por exemplo, bons resultados do trabalho do arquiteto e urbanista quando ele propõe mudanças urbanas significativas, inclusive no Brasil. Se reconhece mundialmente a capacidade dos profissionais locais quando contribuíram para a qualidade das leis urbanas brasileiras (Estatuto da Cidade) ou atuaram produzindo boa arquitetura e urbanismo nas áreas precárias das cidades, sendo, portanto, reconhecidos como aqueles responsáveis pela mudança nessas áreas (FRANÇA et al., 2013). Então quem não valoriza o trabalho do arquiteto não é a sociedade. São os próprios arquitetos que não lutam e ocupam o espaço de suas atribuições. França et al. (2013) afirmam que a exposição midiática de Lúcio Costa e 
Oscar Niemeyer acabou por projetar uma ideia no imaginário das pessoas de que $o$ arquiteto e urbanista projeta apenas grandes obras onde o aspecto plástico se sobrepõe aos aspectos ecológico e humano. Esta projeção afeta, portanto, a formação do arquiteto que, por vezes, entra na escola de arquitetura e começa a se encantar com a ideia de fazer parte do star system da arquitetura local, não tendo a chance de conhecer e se seduzir pela possibilidade de produzir espaços de qualidade para a maior parte da população nas suas diversas variantes.

Considerando o fato de que há uma demanda social da participação do arquiteto e urbanista na resolução dos problemas do espaço habitável, infelizmente essa pendência não está sendo atendida por ainda não se ter encontrado formas de estender o benefício da atuação do arquiteto e urbanista à totalidade da população. Mesmo que, desde 2008, exista uma lei que assegura "às famílias de baixa renda assistência técnica pública e gratuita para o projeto e a construção de habitação de interesse social" (BRASIL, 2008), tornando o trabalho de projetar e construir acessível a toda sociedade, ao estabelecer a possibilidade de famílias com renda de até três salários mínimos ter acesso aos serviços de arquitetura e urbanismo.

Nesse contexto brasileiro de um capitalismo globalizado e agressivo, qual deveria ser o papel da arquitetura e urbanismo? Adotar o viés "mercadófilo" dos projetos arquitetônicos e urbanístico (imobiliários), que se contrapõe ao chamado desenvolvimento sustentável tem sido o caminho escolhido. A abordagem sustentável entra em conflito com a expansão ilimitada do mercado e exige uma nova forma de inteligência projetual para defender o equilíbrio do planeta (SEGRE, 2008). O arquiteto e urbanista poderia partir das questões da sustentabilidade como propiciadora de novas relações sociais, econômicas, políticas e ambientais, preocupadas em preservar a complexidade da vida no País para assim promover o bem-estar da população em bases sustentáveis (SEGRE, 2008).

Obviamente que o futuro da arquitetura e urbanismo está intimamente ligado ao processo de formação dos arquitetos e urbanistas e o que se observa, na maior parte das vezes, é que os cursos de formação acabam sendo extremamente teóricos ou, pior do que isso, superficiais. A universidade forma arquitetos e urbanistas afastados da realidade, mais relacionados à teoria do que à práxis projetual (MARAGNO, 2013). Os cursos acabam sendo incapazes de fornecer ao aluno a possibilidade de uma atuação relevante socialmente, desconstruindo a arquitetura e transformando-a em um espaço de competição pelos "bons" clientes. Em um contexto de uma restrita elite e classe média com capacidade de pagamento, a absorção de mão de obra se torna pequena. Além disso, há uma fraca atuação dos egressos em outras áreas também previstas como de competência dos arquitetos e urbanistas, tais como execução de obras e tecnologia de construção, urbanismo e infraestrutura, meio ambiente, topografia.

Como, portanto, alterar essa lógica que afasta o arquiteto e urbanista da sua vocação de melhorar a qualidade de vida de todos os habitantes por meio da intervenção no espaço habitável? Esse foi o desafio assumido quando se pensou no projeto pedagógico de um novo curso de Arquitetura e Urbanismo em Maceió.

\section{UM PROJETO PEDAGÓGICO INOVADOR}

Tendo em vista a crítica à maneira como a formação do arquiteto e urbanista vem sendo realizada, a oportunidade de pensar em um novo modelo de projeto pedagógico para uma região empobrecida e carente de técnica, como é o Nordeste brasileiro, se mostrou aliciadora de ideias e utopias para a relevância social pretendida da profissão. Nesse sentido definiram-se como eixos temáticos do novo curso: o meio ambiente e a infraestrutura urbana (com ênfase no saneamento e na mobilidade); a 
construção da habitação popular (levando em consideração a topografia e a requalificação em áreas urbanas e rurais); além do urbanismo em pequenas cidades (tratando das questões prementes tais como acessibilidade, parcelamento do solo e desenho urbano). Sendo assim, o curso definiu como foco principal o ato de projetar, no qual as questões arquitetônicas, urbanísticas e paisagísticas seriam tratadas conjuntamente. Todos os projetos elaborados durante a formação deverão contemplar as questões urbanas, aumentando a escala de acordo com a complexidade do tema, de acordo com o amadurecimento e o progresso do aluno.

Logo, o curso "orbitaria" em torno da prática projetual (disciplinas do bloco disciplinar: Projeto de Arquitetura, Urbanismo e Paisagismo) que se serviria de disciplinas conceituais e instrumentais para a sua completa execução ${ }^{1}$, conforme ilustrado na Figura 1 a seguir:

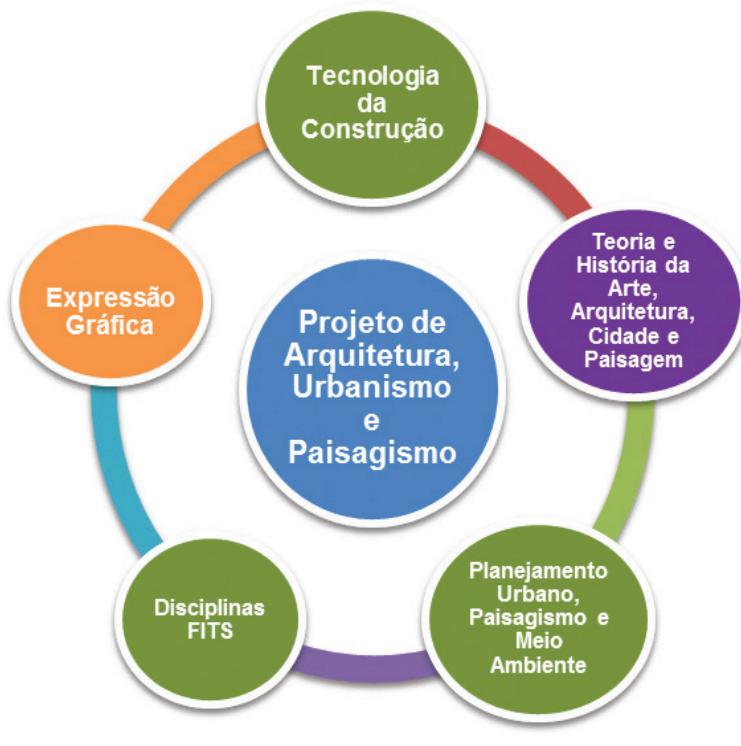

Legenda

Disciplinas integradoras

Disciplinas conceituais e instrumentais

Disciplinas conceituais

Disciplinas instrumentais
A oferta desse novo curso de Arquitetura e Urbanismo visou suprir a lacuna de arquitetos e urbanistas dotados de conhecimentos acerca do processo construtivo concatenado com as necessidades regionais e locais para atuar nas questões urbano-ambientais próprias do tempo atual e da realidade histórica. Tratava-se de conectar cada vez mais as questões da arquitetura e do urbanismo, produzindo espaços de qualidade tanto do ponto de vista dos edifícios quanto da paisagem e do espaço urbano.

O curso proposto trouxe consigo reflexões sobre a essência da arquitetura e do urbanismo no atual contexto mundial da globalização, que exige que todas as sociedades trabalhem o lema "pensar globalmente e agir localmente", incorporando e regionalizando, num processo criativo, novos paradigmas, como: sustentabilidade, equilíbrio social e ecológico, preservação da originalidade local e regional. Simultaneamente, exige o início de um processo de produção do espaço do habitat humano cada vez mais industrializado, com formas inovadoras, visando uma melhoria das condições de vida das futuras cidades, interferindo no espaço e criando soluções que demonstrem o compromisso do arquiteto e urbanista com o exercício da cidadania.
Figura 1. Relação entre os blocos disciplinares e tipos de disciplinas. Fonte: PPC de Arquitetura e Urbanismo da FITs. 
Os objetivos do curso são decorrentes da análise da realidade e dos posicionamentos assumidos nos referenciais e expressam as finalidades da ação educativa proposta por ele. Como objetivo geral, propusemos:

Formar profissionais no campo da arquitetura e urbanismo, conscientes da responsabilidade social e do comprometimento com o desenvolvimento regional, através do empreendedorismo, da criatividade, da prática, da crítica, da reflexão e da transformação em consonância com a realidade na qual está inserido. (FACULDADE INTEGRADA TIRADENTES, 2012).

Embora tenha caráter generalista, ressalta-se que a formação foi pensada de forma a promover uma prática profissional que englobasse tanto o projeto de arquitetura, urbanismo e paisagismo (incluindo a conservação do patrimônio construído e natural por meio de atuação nas questões infraestruturais e ambientais) quanto a construção civil (sobretudo do habitat popular). Além disso, o curso buscará a formação de um profissional capaz de participar na formulação do planejamento urbano e regional, voltado especialmente para o desenvolvimento de pequenas e médias cidades, realidade do estado de Alagoas, de onde se originam muitos dos alunos.

Baseado nos novos critérios, o Projeto Pedagógico implementado busca uma abordagem de ensino mais baseada na prática, ensinando a fazer fazendo, tratando de desenvolver um perfil mais de arquiteto e urbanista construtor (executor), enfatizando além do ato de projetar, a execução de obras e serviços como um espaço profissional importante de ser ocupado, tendo em vista a baixa qualidade e coerência das obras com seus respectivos projetos. Nesse sentido, o curso se organizou em torno de quatro blocos disciplinares principais: Projeto de Arquitetura, Urbanismo e Paisagismo; Planejamento Urbano, Paisagismo e Meio Ambiente; Teoria e História da Arte, Arquitetura, Cidade e Paisagem; Tecnologia da Construção. Há também um bloco disciplinar relacionado à Expressão Gráfica (instrumental de base para a projetação, que poderá ser comum a outros cursos que tenham o desenho como instrumento) e outro bloco disciplinar, com aquelas disciplinas comuns a todos os cursos da instituição que objetivam nivelar os conhecimentos e criar uma identidade própria, ética, cidadã, investigativa e extensionista ${ }^{2}$ de todos os alunos. O Quadro 1 a seguir apresenta o esquema geral da estrutura curricular envolvendo todos os blocos disciplinares.

O eixo estruturador do curso é o bloco disciplinar Projeto de Arquitetura, Urbanismo e Paisagismo, cujas unidades curriculares apresentam conteúdos obrigatórios de integração. Nessas disciplinas o aluno fará a síntese entre arquitetura e urbanismo integrando as matérias conceituais e instrumentais. O bloco disciplinar Planejamento Urbano, Paisagismo e Meio Ambiente, apesar de conter algumas disciplinas mais instrumentais, terá sua maior contribuição na esfera conceitual. Já o bloco Teoria e História da Arte, Arquitetura, Cidade e Paisagem aportará disciplinas de ênfase conceitual. O bloco disciplinar Tecnologia da Construção será prioritariamente instrumental.

Em termos de atividades práticas que serão desenvolvidas dentro do curso, como laboratório de ensino, pesquisa e extensão, utilizando-se as disciplinas de cada bloco disciplinar em trabalho conjunto no Escritório Modelo e Canteiro Experimental em Arquitetura e Urbanismo (EMCE) que será criado, serão promovidas as seguintes ações:

Essa visão da pesquisa e da extensão está definida no Projeto Político Institucional da então Faculdade Integrada Tiradentes (FITs), hoje Centro Universitário Tiradentes (UNIT), que estabelece algumas disciplinas obrigatórias para todos os alunos - entre elas encontram-se as Práticas Investigativas I e II e as Práticas Extensionistas I e II, que nos primeiros quatro períodos de todos os cursos já exigem que os alunos estejam elaborando e executando projetos de pesquisa e extensão. 
- Construção de uma casa popular por ano (recursos obtidos por meio de patrocínios) em cooperação com associações de moradores, servindo de local para aprendizagem dos elementos construtivos para todos os alunos;

- Convênios com municípios para prestar assessoria urbanística a cada ano, observando os aspectos ambientais, de desenho urbano, de infraestrutura e de planejamento;

- Convênios com construtoras para o acompanhamento de obras em troca de bolsas de estudo para seus funcionários.

Quadro 1. Esquema geral da estrutura curricular.

\begin{tabular}{|c|c|c|c|c|c|c|c|c|c|c|}
\hline \multirow{2}{*}{$\frac{\text { Núcleos }}{\text { Períodos }}$} & \multicolumn{2}{|c|}{ Fundamentação } & \multicolumn{7}{|c|}{ Profissionalização } & \multirow{2}{*}{$\frac{\text { TFG }}{10}$} \\
\hline & 1 & 2 & 3 & 4 & 5 & 6 & 7 & 8 & 9 & \\
\hline Ciclos & \multicolumn{2}{|c|}{ Introdução } & \multicolumn{2}{|c|}{ Básico } & \multicolumn{2}{|c|}{ Intermediário } & \multicolumn{4}{|c|}{ Avançado } \\
\hline \multirow{7}{*}{$\begin{array}{l}\text { Blocos } \\
\text { Disciplinares }\end{array}$} & \multicolumn{10}{|c|}{ Projeto de Arquitetura, Urbanismo e Paisagismo (PAUP) } \\
\hline & \multicolumn{10}{|c|}{ Planejamento Urbano, Paisagismo e Meio Ambiente (PUPM) } \\
\hline & \multicolumn{10}{|c|}{ Teoria e História da Arte, Arquitetura, Cidade e Paisagem (THAC) } \\
\hline & \multicolumn{10}{|c|}{ Tecnologia da Construção (TC) } \\
\hline & \multicolumn{10}{|c|}{ Disciplinas de outros cursos (FITS) } \\
\hline & \multicolumn{10}{|c|}{ Expressão Gráfica (EXP) } \\
\hline & \multicolumn{10}{|c|}{ Atividades Complementares } \\
\hline
\end{tabular}

Fonte: PPC de Arquitetura e Urbanismo da FITs.

Como elementos integradores e que reforçariam a proposta de articulação entre arquitetura e urbanismo, o Projeto Pedagógico do curso adotará algumas estratégias que serão desenvolvidas no passo a passo da integralização do curso. Como todas as disciplinas deverão gravitar em torno da prática de projetação e de execução (em arquitetura, urbanismo e paisagismo), haverá a integração entre os conteúdos das disciplinas em termos horizontais (no mesmo semestre) e em termos verticais (entre semestres), e serão ministrados de forma a contemplar graus crescentes de complexidade.

\section{AVALIAÇÃO DAS ESTRATÉGIAS ADOTADAS PARA O ENSINO DE URBANISMO}

Apesar da recente implantação do Projeto Pedagógico, inaugurado em fevereiro de 2014, é possível avaliar preliminarmente algumas das estratégias adotadas para promover a integração entre arquitetura e urbanismo no âmbito da formação. Dentre aquelas adotadas no Projeto Pedagógico do curso de Arquitetura e Urbanismo da FITs, duas já foram implantadas: a introdução do urbanismo no primeiro semestre do curso e o evento integrador Arquitecendo.

Além das disciplinas básicas de qualquer primeiro semestre de curso de Arquitetura e Urbanismo, como Desenho e Geometria, Teoria e História, Metodologia Científica, Fundamentos de Projeto de Arquitetura e Urbanismo etc., o curso da FITs traz em seu primeiro semestre a disciplina Estudos Urbanos: Sociedade, Economia e Meio Ambiente, que trata de conteúdos como: os problemas urbanos contemporâneos e a discussão sobre a cidade brasileira, o conceito e a história da evolução da cidade, a base econômica do desenvolvimento urbano, as funções urbanas, os conflitos sociais e espaciais no meio urbano e a poluição ambiental. Apresentam-se também na disciplina a reforma urbana, o desenvolvimento sustentável e a evolução do pensamento ambiental no Brasil, chegando na Agenda 21 brasileira. Como parte prática da disciplina os alunos realizam uma análise social, econômica e ambiental de uma área de Maceió e apresentam propostas de 
melhorias sociais, econômicas e ambientais em forma de maquete para a área analisada.

Essa estratégia de introduzir as questões urbanas desde o primeiro semestre do curso teve como objetivo o treinamento dos alunos, desde o início, para a visualização das diferentes escalas do espaço habitável. Além da discussão teórica sobre as questões urbanas, os alunos têm a oportunidade de propor melhorias nas áreas visitadas, ou seja, começam a exercitar a prática projetual articulando a arquitetura e o urbanismo.

Como forma de complementar e articular a mesma estratégia, o curso também propõe no primeiro semestre um evento intitulado Arquitecendo que tem por objetivos principais a integração entre discentes e docentes do curso de Arquitetura e Urbanismo, a identificação e construção da identidade desses alunos com o bairro e as comunidades que estão no entorno imediato do campus da faculdade, bem como a construção da identidade do curso, contribuindo para a formação desses estudantes, tornando-os mais confiantes, conscientes e críticos, entendendo a integração entre a arquitetura e urbanismo, muito importante na futura prática profissional.

Acredita-se que interferir na formação e na visão que os estudantes têm da cidade, em um momento no qual o curso está sendo implantado, é uma oportunidade única, pois essa ação é fundamental para criar a tão esperada identidade de curso. Curso esse que, como foi apresentado no início do artigo, tem seu embasamento nos processos criativos e na construção de um olhar integrador no que tange à estética, à cidade, a seus habitantes e modos de morar.

O evento se divide em quatro momentos: encontro, percepção, reencontro e troca.

- Encontro: recepção dos alunos do primeiro período e formação dos grupos de trabalho. São formados quatro grupos de modo aleatório mediante a distribuição de fitas coloridas (quatro cores referentes aos quatro grupos). Formados os grupos, estes terão como "tutores" dois professores do curso que darão as instruções de como o processo perceptivo de investigação urbana será realizado. Cada grupo adotará um tema que norteará a visita aos bairros/comunidades ao redor do campus da faculdade. Dentro dessas áreas encontram-se quatro paisagens bem distintas: dois assentamentos precários, um conjunto residencial popular da Cohab/AL, um bairro residencial de classe média com a presença de empreendimentos de turismo e um grande eixo viário que liga a região da faculdade a outros bairros, inclusive à área de expansão da cidade.

- Percepção: cada grupo segue da faculdade para uma das quatro áreas pré-determinadas. Essa caminhada acontece nos moldes da deriva (metodologia situacionista de investigação urbana que tem como princípio perceber a subjetividade afetiva do lugar). Os alunos devem registrar suas impressões em croquis, fotografias, vídeos e coletas de objetos relacionais que serão utilizados nas oficinas.

- Reencontro: os alunos deverão retornar à faculdade para dar continuidade às atividades. O reencontro é o momento no qual cada participante compartilha sua experiência pessoal com os demais, a fim de formar uma experiência de grupo. Nesse momento são exploradas as potencialidades do lugar e da percepção dos participantes e serão produzidas imagens conceituais dessas experiências vividas e das histórias contadas tecendo uma imagem coletiva.

- Troca: no final do dia, os quatro grupos apresentam seus mapas conceituais da visita, bem como as histórias e as particularidades da experiência. Essa produção é exposta no hall do bloco de salas de aula do curso de Arquitetura e Urbanismo a fim de que possam ser compartilhadas com os demais usuários da Faculdade e, atualmente, com os alunos veteranos do curso. A base para esses mapas foi tecido 
branco na primeira edição do evento - o que ajuda a explicar um pouco mais o nome do evento - e nas edições seguintes optou-se por papel paraná e depois por módulos de MDF conforme pode ser visto nas quatro figuras a seguir:
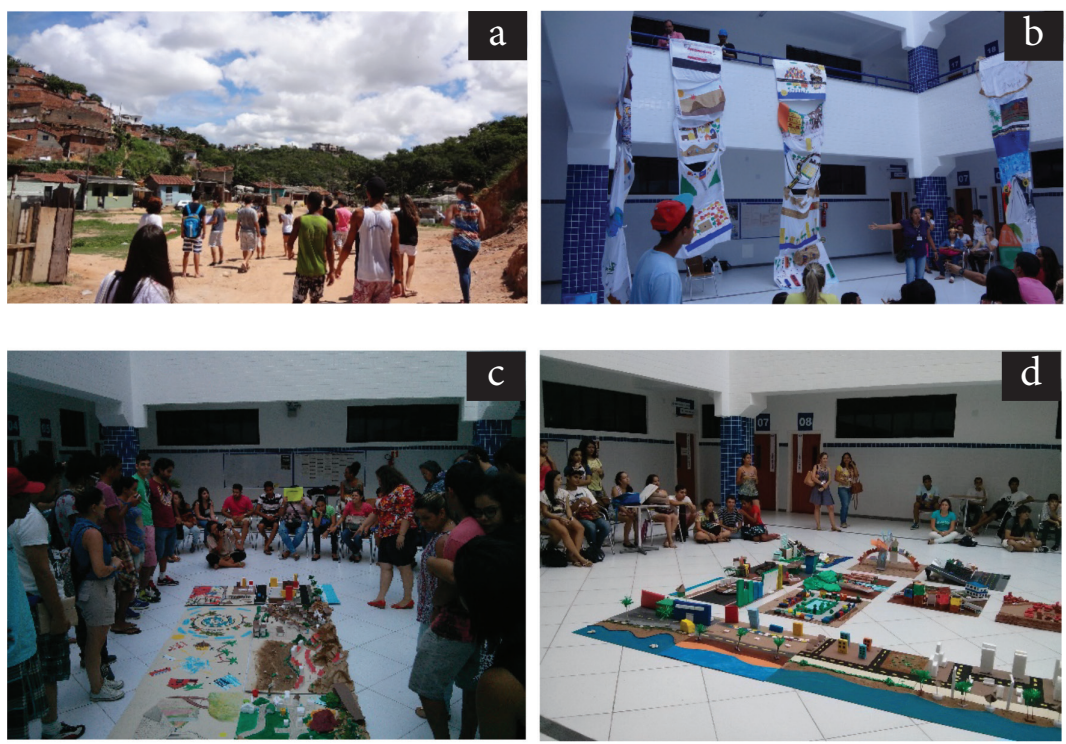

Dessa forma, acredita-se que o Arquitecendo é um evento que permite definir a identidade do curso de Arquitetura e Urbanismo da FITs, tornandose um referencial na formação dos alunos e na atuação dos professores.

Alguns dos professores envolvidos na organização do evento (de áreas de ensino diferentes da de urbanismo) trouxeram algumas contribuições para a avaliação da experiência ao responder as seguintes questões:

1) O que você acha de introduzir os Estudos Urbanos no primeiro semestre do curso de Arquitetura e Urbanismo?

2) O exercício do Arquitecendo trouxe algum avanço na aprendizagem do aluno?

3) Ao projetar, os alunos conseguem articular melhor a arquitetura e o urbanismo?

As respostas à primeira questão foram muito positivas, cada um percebendo dentro da sua área de atuação diferentes contribuições como

A experiência tem se mostrado muito válida, pois tem indicado que os alunos despertam um novo olhar para a cidade. Começam a se questionar sobre estrutura física, distribuição do espaço, melhorias, segurança, entre outros. Passam a prestar mais atenção na cidade em que vivem e trazem essas experiências para a sala de aula. (informação verbal).

Seguindo essa mesma ideia, outro professor complementa a fala afirmando que a disciplina

Tem tornado os alunos do curso de Arquitetura e Urbanismo mais conscientes do papel social do arquiteto, além de torná-los mais críticos e questionadores quanto aos aspectos da cidade em que vivem. A impressão é que o aluno começa o curso com um olhar mais maduro, diferente das turmas do ensino de arquitetura convencional, onde as problemáticas e o pensamento urbano só são abordados a partir do quarto período. (informação verbal).
Figura 2. (a) Momento da "percepção" em um dos assentamentos visitados, em 2014. (b) Momento da "troca" na edição do Arquitecendo 2014.1. (c) Momento da "troca" na edição do Arquitecendo 2014.2. (d) Momento da "troca" na edição do Arquitecendo 2015.1. Fonte: Acervo do curso de Arquitetura e Urbanismo da FITS. 
Outra docente vai um pouco mais além, afirmando que essa disciplina é "essencial para os alunos e futuros arquitetos, pois é necessário desde o início do curso tentar fazê-los entender as relações de espaço para além da edificação" (informação verbal).

Com relação ao questionamento sobre a importância do evento Arquitecendo, as percepções dos docentes também se mostraram muito positivas: "sinto que os alunos passaram a criar mais vínculo de identidade com localidade estudada. Passou a existir uma preocupação com a comunidade que fomenta ideias espontâneas (além da sala de aula) para solucionar alguns problemas" (informação verbal).

Vejo que os alunos entendem melhor não só a cidade em que vivem, como também a própria realidade. Conseguem enxergar de outra forma os problemas urbanos atuais e conviver melhor com a diversidade. Muitos vão além e já tentam pensar em soluções, alternativas e começam a compreender melhor o seu papel na sociedade. (informação verbal).

Sobre a terceira questão apenas um dos professores, que é da área de projeto, colocou sua opinião, afirmando:

Ainda sinto que esse aspecto não mudou, mas acredito que o problema seja a abordagem da disciplina de projeto que não incluiu a análise do entorno como parte dos condicionantes projetuais. Contudo, caso a metodologia de projeto mudasse, acredito que o olhar analítico dos alunos seria diferente do dos alunos que ainda não tiveram as disciplinas de urbanismo. (informação verbal).

Como a experiência é bem recente e os professores ainda estão construindo uma metodologia projetual mais articuladora entre arquitetura e urbanismo, espera-se mais adiante poder avaliar, com mais precisão, os impactos dessas estratégias adotadas.

Da mesma forma, para a elaboração deste artigo decidiu-se fazer alguns questionamentos aos alunos sobre suas ideias prévias sobre o que seria um curso de arquitetura e urbanismo, suas percepções iniciais do curso e suas considerações sobre a disciplina de Estudos Urbanos: Sociedade, Economia e Meio Ambiente e do evento Arquitecendo, e também se houve alguma mudança de percepção sobre o conteúdo do curso. Em virtude da exiguidade do prazo para conclusão do artigo e a coincidência com época de provas e conclusão do semestre, poucos alunos formalmente se manifestaram respondendo a um formulário online proposto. $\mathrm{O}$ formulário fez cinco perguntas de resposta obrigatória:

1) Quando você optou pelo curso de Arquitetura e Urbanismo, o que você imaginou como atividades do arquiteto e urbanista?

2) O que era para você a arquitetura?

3) O que era para você o urbanismo?

4) O que representou para você o evento Arquitecendo na sua compreensão da arquitetura e do urbanismo?

5) Como você vê hoje a relação entre arquitetura e urbanismo?

As respostas à primeira pergunta foram muito gerais, referindo-se ao curso de Arquitetura e Urbanismo como um curso no qual se desenharia casas e se utilizaria a criatividade. As respostas a essa pergunta na verdade refletem já alguma influência das disciplinas cursadas. Para uma melhor avaliação das estratégias, essa pergunta (assim como a pergunta 2 e 3) deverá se aplicada na primeira semana de aula do próximo semestre, para depois se verificar a eventual mudança de ponto de vista dos alunos já no final do semestre letivo. 
As respostas às perguntas 2 e 3 são também bem gerais e enfatizam a arquitetura como construção de sonhos, principalmente de casas. As respostas também falam em criação de espaços nos quais a estética, o conforto e a organização do espaço se destacam do ponto de vista da arquitetura. Já do urbanismo se fala em funcionamento e organização das cidades, ruas, praças, paisagens.

As respostas à pergunta 4, por outro lado, foram muito mais pessoais (diferentemente das anteriores), demonstrando mudanças de pensamento e aquisição de novos conhecimentos. As falas revelam um impacto profundo no conhecimento do que é a realidade local e a possibilidade de transformála por meio da profissão que os estudantes começam a se preparar para um dia exercer: "é uma experiência única não só para o curso, mas para a ética humana" (informação verbal). Há também uma compreensão da relação intrínseca entre a Arquitetura e o Urbanismo: "só entendi de verdade o que é Arquitetura e Urbanismo depois de ter participado do evento e do projeto" (informação verbal).

Começa-se a pensar na possibilidade de trabalhar como arquiteto e urbanista também nas comunidades, e que os moradores dessas áreas, assim como qualquer cidadão, têm o direito de sonhar com a sua casa projetada por um arquiteto e urbanista, além de entender que um bom projeto urbano é fundamental para a qualidade do espaço arquitetônico:

[Participar do Arquitecendo] representou o lado do arquiteto e urbanista de lidar com o sonho de um cliente, pois meu projeto é futuramente realizar mudanças na comunidade, e foi importante ter esse primeiro contato com os moradores, para ver o que eles acham do projeto urbano para depois ser realizado o arquitetônico. (informação verbal).

O entendimento da realidade urbana local, a curiosidade, a vontade de transformar a si próprio e aos espaços para o benefício comum parece ser uma "verdade" adquirida que, com certeza, marcará os anos futuros do aprendizado profissional:

[Participar do Arquitecendo] representou que não existe só a realidade em que eu vivo. Que a minha volta existem outras questões com as quais não convivo, mas estão ali. Que se deve conhecer melhor o ambiente em que se vive e ao redor dele. Que se pode melhorar um lugar com a transformação de elementos do espaço. O Arquitecendo fez com que os olhares dos futuros arquitetos e urbanistas ficassem mais aguçados, mostrando elementos e detalhes urbanos que não notaríamos se não estivéssemos nesse curso. (informação verbal).

A última pergunta ensaia uma síntese da compreensão da arquitetura e urbanismo após o Arquitecendo, e a discussão teórica e o trabalho prático que se realizam na disciplina Estudos Urbanos: Sociedade, Economia e Meio Ambiente, sobre a área visitada no evento. Os alunos mostram um aprendizado, obviamente ainda incipiente, das possibilidades profissionais que o curso oferece, contemplando ética e estética, que sempre foram as bases da profissão: "[arquitetura e urbanismo] em uma relação de complemento, na qual a arquitetura cria espaços e o urbanismo os organizam em meio a cidade" (informação verbal). 0 impacto no entusiasmo e paixão pela profissão é marcante: "foi excepcional, pois aprendi que não existe arquitetura sem urbanismo e que ele, por sua vez, faz ter sentido tudo aquilo que se é construído ou idealizado" (informação verbal) - obviamente que com algum entusiasmo e utopia a mais, indispensáveis para a juventude que precisa ter liberdade para ampliar seus horizontes criativos e éticos em busca de uma sociedade melhor, na qual o trabalho do arquiteto e urbanista recupera seu valor histórico e sua relevância social transformadora. 
Hoje vejo o curso com outros olhos. Apesar de não ter concluído, vejo que não é só algo estético. Tão importante quanto a construção em si, o arquiteto e urbanista tem o trabalho ético de arquitetar literalmente um espaço melhor para todos. Através deste é possivel formar novos costumes, formas de pensar, grupos de encontro, espaços inimagináveis. A imaginação, algo primordial no início da história humana, vem se defasando pelas tecnologias e a alienação cotidiana, $e$ cabe ao arquiteto o dever de guiar a sociedade para uma melhor convivência entre os seres humanos. (informação verbal).

Além das respostas ao formulário, foi possível recolher manifestações espontâneas por parte dos alunos sobre o que foi o evento: "a gente deveria ter Arquitecendo todo mês"; "foi muito bom, a gente começou a ver a cidade com outros olhos" (informações verbais).

\section{CONCLUSÃO}

A experiência, que teve início em 2014, ainda é muito recente. No entanto, há evidências de que as opções propostas têm um grande potencial transformador. A aproximação com as questões urbanas e o contato com a realidade local modificaram comportamentos e atitudes inicialmente pouco abertas ao contato com outros grupos sociais. A visita e o trabalho em uma comunidade de baixa renda vizinha à faculdade desconstruíram estereótipos e, de maneira surpreendente, impulsionou todos os trabalhos para aquela área, o que era impensável em outras escolas de arquitetura, onde os alunos "fogem" dessas áreas de trabalho. A compreensão de que a arquitetura e o urbanismo são disciplinas capazes de melhorar a qualidade de vida das pessoas através da projetação de espaços de qualidade já permeia o pensamento desses jovens estudantes que se apaixonaram pelo curso e querem dessa forma contribuir para o desenvolvimento da cidade. Do primeiro ao segundo semestre não se contabilizou nenhuma evasão de alunos decorrente de insatisfação com o andamento do curso, há muito a fazer para que essa integração entre a arquitetura e urbanismo se materialize, e o resultado dessa experiência será divulgado para críticas e contribuições.

\section{REFERÊNCIAS}

BICCA, P. Arquiteto, a máscara e a face. São Paulo: Projeto, 1984.

BRANDÃO, P. Profissão de arquitecto identidade e prospectiva: estudos de caso. Tese (Doutorado). Barcelona: Universidade de Barcelona, 2005.

BRASIL. Lei no 11.888, de 24 de dezembro de 2008. Assegura às famílias de baixa renda assistência técnica pública e gratuita para o projeto e a construção de habitação de interesse social e altera a Lei no 11.124, de 16 de junho de 2005. 2008. Brasília, DF: Casa Civil. Disponível em: <http://www.planalto. gov.br/ccivil_03/_Ato2007-2010/2008/Lei/ L11888.htm>. Acesso em: 4 fev. 2016.

FACULDADE INTEGRADA TIRADENTES. Projeto pedagógico do curso de Arquitetura e Urbanismo. Maceió: FITS, 2012.

FRANÇA, E.; SALLES, F.; LOUREIRO, J. C.; MARCONDES, L.; BERTOLDI, M.; LUZ,
R. P. Por que a sociedade não valoriza o trabalho do arquiteto? Revista AU [online], São Paulo, Edição 231, jun. 2013. Disponível em: <http://au.pini.com.br/arquiteturaurbanismo/231/artigo290413-1.aspx>. Acesso em: 15 maio 2015.

LAUANDE, F. As velhas e novas máscaras do arquiteto. Arquitextos [online], São Paulo, ano 06, n. 062.00, jul. 2005. Disponível em: <http://www.vitruvius.com.br/revistas/ $\mathrm{read} /$ arquitextos/06.062/440>. Acesso em: 15 maio 2015

MARAGNO, G. V. Quase 300 cursos de Arquitetura e Urbanismo no país: como tratar a qualidade com tanta quantidade? Algumas questões sobre qualificação e ensino no Brasil. Arquitextos [online], São Paulo, ano 14, n. 161.07, out. 2013. Disponível em: <http://www.vitruvius.com.br/revistas/ read/arquitextos/14.161/4930>. Acesso em: 15 maio. 2015. 
ROGGERO, R. A vida simulada no capitalismo: formação e trabalho na arquitetura. São Paulo: Letra e Voz, 2010.

SEGRE, R. Arquitetura precisa de ideologia? Revista AU [online], São
Paulo, Edição 166, jan. 2008. Seção Fato e Opinião: Fórum. Disponível em: <http:// au.pini.com.br/arquitetura-urbanismo/166/ artigo70741-1.aspx>. Acesso em: 15 maio 2015.
Mônica Peixoto Vianna monica_vianna@yahoo.com

Débora Barros Cavalcanti debora_cavalcanti@hotmail.com 